\title{
Influence of Water Injection Fracturing on Crack Damage in Soft Coal and Application in Gas Extraction
}

\author{
Zhirong Wang1, Jianshi Jin'1, Zhongyang Hang', Xiangzhi Hu ${ }^{2}$ \\ ${ }^{1}$ School of Environment and Water Conservancy Engineering, Zhengzhou University, Zhengzhou, China \\ ${ }^{2}$ Gas Well Engineering Research Center of Henan, Zhengzhou, China \\ Email: wangzhirong513@sina.com, jinbeckham10@163.com, hzy2008kobe@sohu.com, \\ yzhuxiagnzhi@126.com
}

Received November 2013

\begin{abstract}
In order to study the hypotonic and rheological particularity of "three soft" coal seam in west Henan, China, this paper explored the stress and damage characteristics of crack in coal under condition of water injection fracturing based on ABAQUS platform; The cohesive element in T-P damage evolution criterion was used to describe the approximately linear relationship between crack width and extending distance in soft coal. The simulation results show that stress evolution and crack damage in soft coal is a gradually developing process under condition of water injection fracturing. When the static pressure is $4-10 \mathrm{MPa}$, and the injection time is about 1 - 2 hours, the damage range of crack in soft coal can basically reach an ideal data of $80-100 \mathrm{~m}$, and then greatly improve the hypotonic performance of "three soft" coal seam.
\end{abstract}

\section{Keywords}

“Three Soft” Coal Seam; Directional Water Injection Fracturing; Crack Damage; Gas Extraction

\section{Introduction}

Coalbed methane (CBM) resources are very rich in Henan province, China. However, the technical problems about low permeability, pressure, saturation and high metamorphic grade in Western Henan coal field especially in "three soft" mining area have not been solved. By now the production of CBM and efficiency of wells are very poor, the extraction rate remains around $25 \%$ and still can’t achieve efficient utilization of CBM [1]. Water fracturing technology is widely used in engineering fields especially in oil and gas extracting industry [2,3,4], but theoretical research about coal seam with low permeability is rarely seen.

In recent years, with the development of rock mechanics test and computer simulation technology, many gas permeability research achievements begin to appear in academia. W. J. Sommerton et al. studied the influence of stress on the permeability of coal [5]; Chinese scholars Jupeng Tang, Yishan Pan [6] found the relation between effective stress and the seepage properties of CBM desorption through analytic seepage experiment research of CBM under pressure. 
So far, great progress has been made in the theory of gas seepage characteristics under stress and gas migration rule under low permeability condition also has been expounded, But systematic analysis of a series of basic theories such as key geological problems about extraction technology of gas in soft coal and fracture law of soft coal under water fracturing condition have not been formed, and research about stress and strain of soft coal under water fracturing condition and dynamic cracking process of coal body after fracturing are still in blank. This paper taking Gaocheng Coal Mine in Henan as an example, established numerical simulation method through the secondary development of ABAQUS and combined with rock damage and Biot consolidation theory, then discussed the theory and application of the stress and strain of soft coal after fracturing, damage extension of crack and gas permeability.

\section{Mathematical Model}

Water fracturing is to inject high presser water into coal seam according to its occurrence, and make the gas-containing layer produce fissure or larger pore along a certain direction after a period of static force effect, and enhance its permeability [7]-[8]. When pressure water flow acts on the original crack or the near parts, it will strongly affect the stress and seepage field nearby. Damage and fracture phenomenon begin to appear in the cracks without gas and the coal near them, the permeability changes accordingly which makes the gas permeate to the fracture channel. Gas permeation intensifies the damage of rock and this process is a typical migrate process of CBM boost by the change of permeability of damaged rock caused by stress field. Now the study on the permeability of broken rock is more mature and has achieved some results [9]-[10]. This paper will apply the numerical simulation method under coupling condition of stress-damage-seepage to verify these results and apply to practice.

\subsection{Creep Test Model}

This paper analyzed the deformation of soft coal according to the creep defined by extended D-P model provided by ABAQUS. The creep rule in ABAQUS means creep is defined by equivalent uniaxial creep. Methods provided by the software include time hardening power function method, user subroutine method, strain hardening power function method and Singh-Mitchell method, method mentioned in this paper is time hardening power function. When the stress on materials remains the same, creep rate and strain are given as follows:

$$
\begin{aligned}
& \frac{d \varepsilon}{d t}=A\left(\sigma^{-c e}\right)^{n} t^{m} . \\
& \varepsilon=\frac{A}{m+1}\left(\sigma^{-c e}\right)^{n} t^{m+1} .
\end{aligned}
$$

where $\frac{d \varepsilon}{d t}$ is creep rate, $\sigma^{-c e}$ is equivalent creep stress. Equation (1) can be seen as three-parameter constitutive relation formula which describes the creep properties of coal, where parameter $A$ reflects the magnitude order of creep rate and the structure and combination of coal, parameter $m$ controls the decrease rate of creep over time, and parameter $n$ reflects the effect of deviator strain on creep.

\subsection{Damage-Permeability Coupling Model}

The existing equations between permeability and stress or strain have some limitations, and it is very difficult to analyze the variation trend of the permeability after rock broken. Therefore, damage mechanics can be introduced to relate them together. Numerical model and the relationship between damage factor and porosity are given as follows:

$$
\begin{gathered}
D=\frac{n_{0}-n}{n_{0}-n_{s}} . \\
n=n_{0}-D\left(n_{0}-n_{s}\right) .
\end{gathered}
$$

where $n_{0}$ is initial porosity of rock mass, $n_{s}$ is porosity of rock which reaches ultimate strength. When material is completely destroyed, namely $n=n_{s}$, the damage variable $D=1$; when there is no damage, namely $n=n_{0}$, the 
damage variable $D=0$. The relationship between permeability and damage is given by:

$$
k=\frac{n}{K_{z} S_{v}^{2}}=\frac{n_{0}-D\left(n_{0}-n_{s}\right)}{K_{z} S_{v}^{2}} .
$$

The stress and strain are changing all the time during the process of hydraulic fracturing, therefore, the dynamic evolution between porosity and permeability must be taken into consideration, and evolution process can be expressed by:

$$
\left\{\begin{array}{l}
k=k_{0}\left[\frac{1}{n}\left(1+\varepsilon_{v}\right)^{3}-\left(\frac{1-n_{0}}{n_{0}}\right)\left(1+\varepsilon_{v}\right)^{-1 / 3}\right]^{3} \\
n=1-\frac{1-n_{0}}{\varepsilon_{v}}
\end{array}\right.
$$

where $n_{0}$ is initial porosity, $k_{0}$ is initial permeability coefficient, and both of them can be getting from geotechnical test and field test, $\varepsilon_{v}$ is the total volume strain of materials.

\section{Numerical Simulation and Analysis}

Take Gaocheng coal mine in Dengfeng, Henan, China, as an example, the 3D finite element numerical calculation model was established with ABAQUS and according to the main gas geology characteristics in mining area. The geological parameters of this coal mine are as follows: the average thickness of main coal seam is $3.10 \mathrm{~m}$, its inclination is $20^{\circ}$, and the thickness of coal seam in typical "three soft" area is about $4.5 \mathrm{~m}$, the central part of coal seam contains one layer of dirt band whose thickness is $0.33 \mathrm{~m}$, and the burial depth of coal mine is $500 \mathrm{~m}$ now. The measured gas pressure is $2.6 \mathrm{MPa}$, gas content is about $20.6 \mathrm{~m}^{3} / \mathrm{t}$. Initial diffusion velocity of gas $\triangle \mathrm{P}$ $=17.42 \mathrm{~L} / \mathrm{min}$, permeability coefficient of coal seam $\lambda=0.0053 \mathrm{~m}^{2} /\left(\mathrm{MPa}^{2} \cdot \mathrm{d}\right)$.

The extraction test hole is chosen as center of directional fracturing simulation area, namely a cylinder with height of $20 \mathrm{~m}$ and radius of $200 \mathrm{~m}$. Type of high-pressure grouting pump is 2TGZ-120/105, and its maximum grouting pressure is $10.5 \mathrm{MPa}$. The length of water injection pipe is $2 \mathrm{~m}$, and its location is between floor and dirt band, and the injection direction is along the occurrence of coal seam to the front of coal wall. DruckerPrager model was chosen as model of coal seam, initial porosity is 3.69\%, initial permeability coefficient is 2.33 $\times 10^{-6} \mathrm{~cm} \cdot \mathrm{s}^{-1}$, viscosity coefficient of water is $1 \times 10^{-6} \mathrm{kPaS}$, injection pressure is $5 \mathrm{MPa}$ and injection rate is 2.3 $\mathrm{m}^{3} / \mathrm{min}$, time of simulation is 2 hours. The radial water flow through spiral tube finally formed a loose cylinder with center of injection pipe, its radius is R, the model is shown in Figure 1.

\subsection{Stress Evolution of Crack Damage}

When the material of crack tip is elastic-plastic medium, the cloud picture of water pressure development process ( $y=10 \mathrm{~m}$ section) in each period is shown in Figure 2. The seepage in coal seam develops to the right side along initial fissure and reaches $34 \mathrm{~m}$ in $30 \mathrm{~min}$ as shown in Figure 2(a), and a wide range of green high stress zone appears at crack tip. This is mainly due to the effect of secondary stress caused by water injection, and directly results in the change and adjustment of underground pore fissure, and then lead to additional seepage of groundwater along the fissure. As injection continues and head loss increases, the fracture radius increases gradually and reaches $58 \mathrm{~m}$ after $60 \mathrm{~min}$ and high stress zone decreases significantly (Figure 2(b)); The crack expands to $80 \mathrm{~m}$ after $90 \mathrm{~min}$, and the high stress zone at crack tip basically disappears and fracturing effect

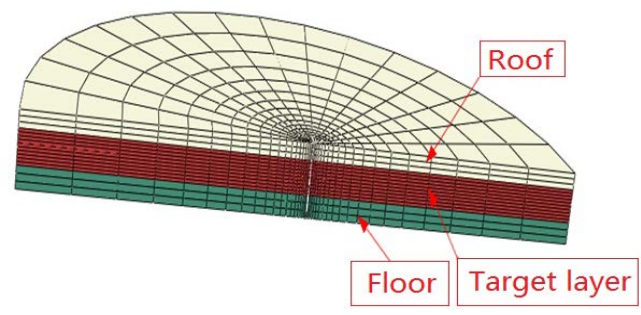

Figure 1. Bedding injection fracturing model of soft coal. 


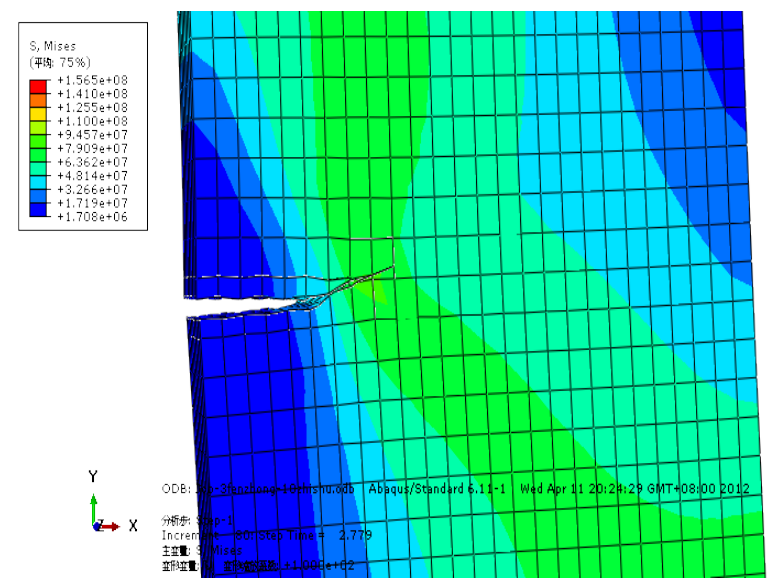

(a)

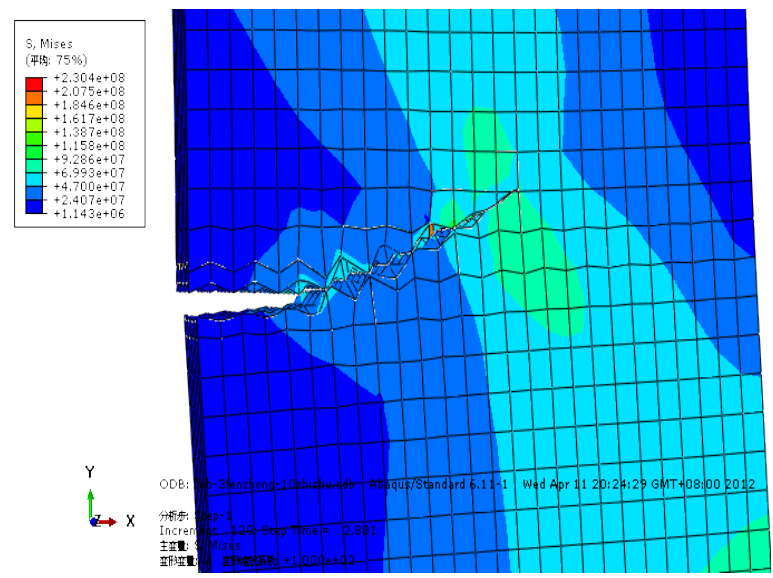

(c)

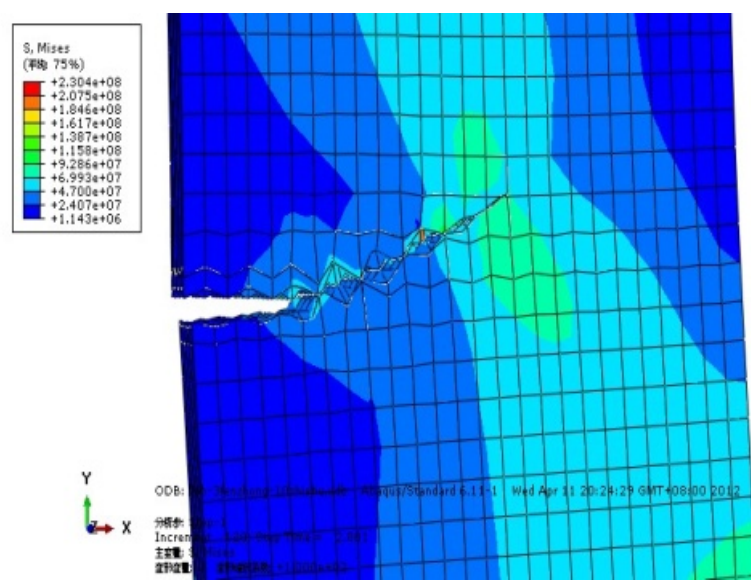

(b)
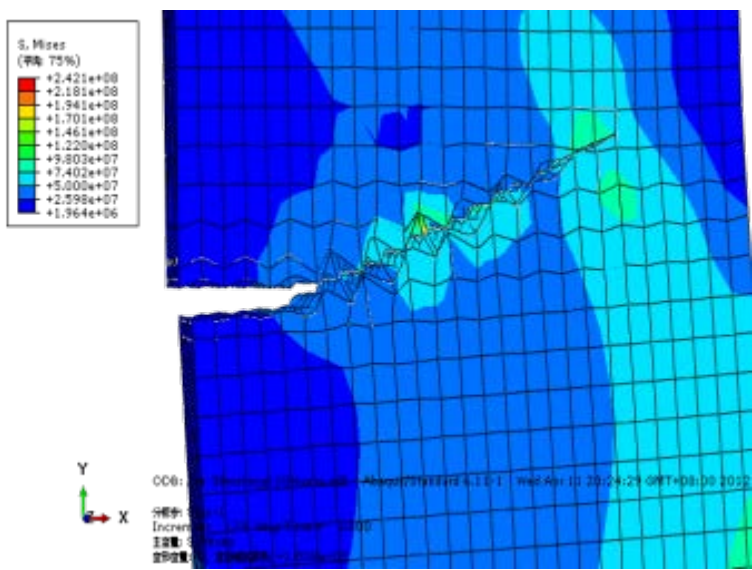

(d)

Figure 2. The stress development nephogram of injection fracturing process in coal seam. (a) $30 \mathrm{~min}$; (b) $60 \mathrm{~min}$; (c) $90 \mathrm{~min}$; (d) $120 \mathrm{~min}$.

becomes worse and worse (Figure 2(c)); The whole high stress zone disappears after 120 min and the extension of crack also stops at $107 \mathrm{~m}$ (Figure 2(d)).

\subsection{Deformation Characteristics of Crack Damage}

The relationship among fracture radius, injection pressure, time and their optimal combination are related to the efficiency of gas extraction. Damage factor of cohesive element changes with the pressure, and damage displacement around fracturing hole along fracturing direction is shown in Figure 3.

Figure 4 shows the extraction rates before and after fracturing, it indicates that the extraction rate differs significantly before and after fracturing, and also differs when using different methods. Extraction rate of bedding fracturing is the highest and up to $0.95 \mathrm{~m}^{3} / \mathrm{s}$, rate of vertical fracturing comes the second, and rate of the coal seam without fracturing is the lowest. The highest rates at the same time are basically 100 times of the lowest, and the maximum multiple can be 131 while the minimum multiple is 68 . Therefore, water fracturing can improve the extraction rate and permeability of coal seam significantly, and the effect of bedding fracturing is most obvious.

\subsection{Load Condition of Crack Damage}

Under hydrostatic pressure value is 4MPa, the maximum principal stress damage coefficient on the left side of coal seam reaches 0.948 and it is close to completely destroyed. As the pressure increases to $4.5 \mathrm{MPa}$, the damage coefficient reaches critical value $(D=1)$, this pressure is slightly larger than the theoretical value as part of 


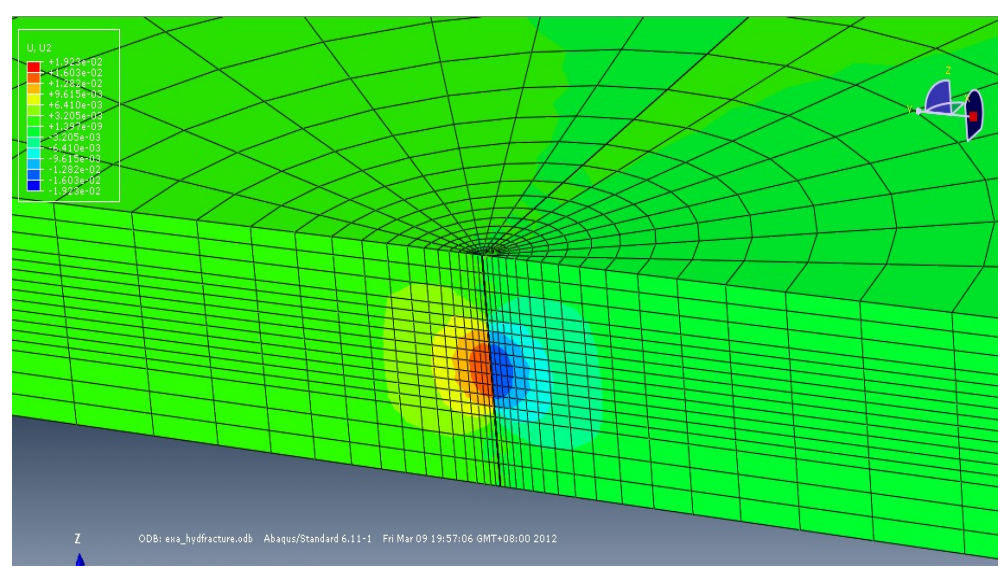

Figure 3. Damage displacement around fracturing hole.

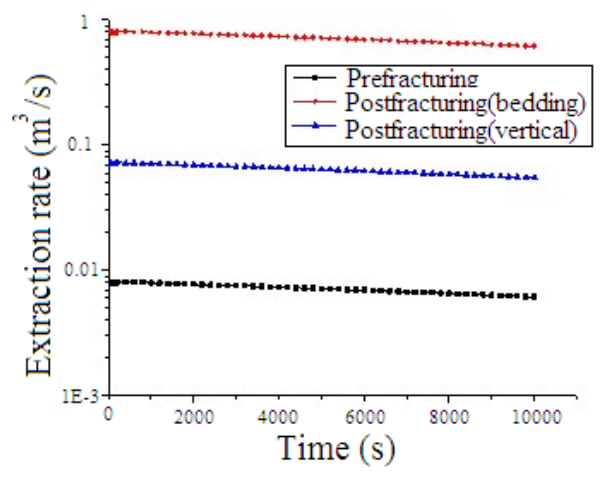

Figure 4. Comparison of extraction rate.

the pressure flow lost in fracturing process, and it is very close to the initial pressure of cohesive elements in this paper. Therefore, the initial pressure of 4.5 MPa is reasonable (Figure 5).

When apply modified Taft seismic data on the model, and set pulse frequency at $10 \mathrm{~Hz}$, the dynamic loads values of cohesive elements with damage factor $D=1$ are slightly lower than the corresponding static values. This indicates that cohesive elements are easier to fatigue, and faster to damage. From another point of view, the difference between dynamic and static damage factors is very small, and the maximum difference is 0.1 (Figure 5), which shows that soft coal has good seismic and isolation effectiveness, namely the crack is difficult to close after fractured.

\section{Test Data and Extraction Effect}

Ground directional water injection fracturing was conducted in 6 drill holes in the test field of Weicun coal mine in Jiaozuo, Henan, China, on September 26, 2007. $\mathrm{G}_{10-002}$ hole is located in a certain mining working face, it's $85 \mathrm{~m}$ away from F5 fault on the east and 110m away from F9 fault on the west. In order to avoid the influence of two boundary faults, the design value of injection pressure is $5 \mathrm{MPa}$, injection time of east fault is 1.5 hours and 2 hours for the west one.

Test data from SN338HR digital seismograph indicate that length of crack at the east side of drilling hole is $82.4 \mathrm{~m}$ and the length of the west one is $109.5 \mathrm{~m}$, which fully verify the simulation results. As is shown in Table 1, because the location is closer to crack, extraction concentration of holes No.1, 19, 20 are 2 - 3 times that of holes No.72, 166, and the average volumes are also much bigger.

\section{Conclusions}

Directional water injection fracturing can significantly improve gas extraction rate. Simulation calculation and field test can indicate the follows: 


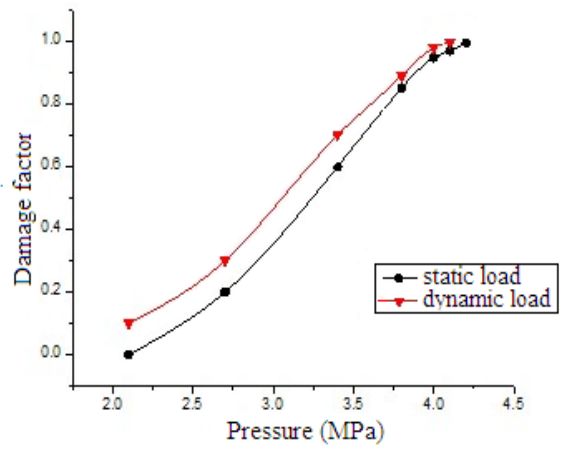

Figure 5. Damage factors under different loads.

1) Water injection can lead to stress concentration at the crack tip and expand the damage zone of crack. When injection pressure is $4-10 \mathrm{MPa}$ and time is around 2 hours, the influence radius can basically reach an ideal data of $80-100 \mathrm{~m}$, and the initial extraction load could be 4.5 Mpa.

2) Water injection can promote the damage of crack, but the opening degree of crack is significantly affected by confining pressure, the relationship between width of crack and extended distance is approximately linear.

3) Gas extraction efficiency after water injection can be improved 100 times, and extraction rate of single well can reach $40 \%-50 \%$, and the fading period extends from 7 days to 1000 - 1500 days, which can basically meet the monthly output target of $1000-2000 \mathrm{~m}^{3}$. This conclusion can provide valuable reference for similar projects and has important strategic significance to the development and utilization of CBM.

\section{References}

[1] Wang, Z.R., Chen, L.X., Cheng, C.R. and Li, Z.X. (2007) Forecast of Gas Geological Hazards for “Three-Soft” Coal Seams in Gliding Structural Areas. Journal of China University of Mining and Technology, 17, 484-488. http://dx.doi.org/10.1016/S1006-1266(07)60130-8

[2] Meyer, B.R. and Bazan, L.W. (2011) A Discrete Fracture Network Model for Hydraulically Induced Fractures Theory. SPE Hydraulic Fracturing Technology Conference, The Woodlands, 24-26 January 2011, 216-225.

[3] Olson, J.E. and Dahi-Taleghani, A. (2009) Modeling Simultaneous Growth of Multiple Hydraulic Fractures and Their Interaction with Natural Fractures. SPE Hydraulic Fracturing Technology Conference, The Woodlands, 19-21 January 2009, 118-121.

[4] Wang, J.J., Zhang, H.P., Zhao, M.J. and Lin, X. (2009) Mechanisms of Hydraulic Fracturing in Cohesive Soil. Water Science and Engineering, 2, 95-102.

[5] Sommerton, W.J., Soylemezoglu, I.M. and Dudley, R.C. (1975) Effect of Stress on Permeability of Coal. International Journal of Rock Mechanics and Mining Sciences \& Geomechanics Abstracts, 12, 129-145. http://dx.doi.org/10.1016/0148-9062(75)91244-9

[6] Tang, J.P., Pan, Y.S., Li, C.Q. and Shi, Q. (2006) Experimental Study of Desorption and Seepage of Coalbed Methane under Solid-Fluid Coupling. Journal of China University of Mining \& Technology, 35, 274-278.

[7] Louis, C. (1969) A Study of Ground Water Flow in Jointed Rock and its Influence on the Stability of Rock Masses. 10th Edition, Imperial College of Science and Technology, London.

[8] Biot, M.A. (1941) General Theory of Three-Dimensional Consolidation. Journal of Applied Physics, 12, 155-164. http://dx.doi.org/10.1063/1.1712886

[9] Yin, G.Z., Li, X.Q., Zhao, H.B. and Li, X.S. (2008) Experimental Research on Effect of Geostress on Outburst Coal's Seepage. Chinese Journal of Rock Mechanics and Engineering, 27, 2557-2561.

[10] Hu, G.Z., Wang, H.T., Fan, X.G. and Yuan, Z.G. (2008) Investigation on Law of Methane Gas Flow in Coal with Coal-Gas Outburst Hazard and Low Permeability. Chinese Journal of Rock Mechanics and Engineering, 28, 25272534. 